\title{
Home care assistants' perspectives on detecting mental health problems and promoting mental health among community-dwelling seniors with multimorbidity
}

\author{
This article was published in the following Dove Press journal: \\ Journal of Multidisciplinary Healthcare \\ 23 February 2016 \\ Number of times this article has been viewed
}

\author{
Åke Grundberg ${ }^{1,2}$ \\ Anna Hansson ${ }^{2}$ \\ Dorota Religa' \\ Pernilla Hillerås ${ }^{1,2}$ \\ 'Division of Neurogeriatrics, \\ Department of Neurobiology, Care \\ Sciences, and Society, Karolinska \\ Institutet, Huddinge, ${ }^{2}$ Sophiahemmet \\ University, Stockholm, Sweden
}

Introduction: Elderly people with multiple chronic conditions, or multimorbidity, are at risk of developing poor mental health. These seniors often remain in their homes with support from home care assistants (HCAs). Mental health promotion by HCAs needs to be studied further because they may be among the first to observe changes in clients' mental health status.

Aim: To describe HCAs' perspectives on detecting mental health problems and promoting mental health among homebound seniors with multimorbidity.

Methods: We applied a descriptive qualitative study design using semi-structured interviews. Content analyses were performed on five focus group interviews conducted in 2014 with 26 HCAs.

Results: Most HCAs stated that they were experienced in caring for clients with mental health problems such as anxiety, depression, sleep problems, and high alcohol consumption. The HCAs mentioned as causes, or risk factors, multiple chronic conditions, feelings of loneliness, and social isolation. The findings reveal that continuity of care and seniors' own thoughts and perceptions were essential to detecting mental health problems. Observation, collaboration, and social support emerged as important means of detecting mental health problems and promoting mental health.

Conclusion: The HCAs had knowledge of risk factors, but they seemed insecure about which health professionals had the primary responsibility for mental health. They also seemed to have detected early signs of mental health problems, even though good personal knowledge of the client and continuity in home visits were crucial to do so. When it came to mental health promotion, the suggestions related to the aim of ending social isolation, decreasing feelings of loneliness, and increasing physical activity. The results indicate that the HCAs seemed dependent on supervision by district nurses and on care managers' decisions to support the needed care, to schedule assignments related to the detection of mental health problems, and to promote mental health. Keywords: home care assistants, mental health promotion, municipal care, older people, Sweden

\section{Introduction}

The older population is increasing in Sweden, ${ }^{1}$ as it is in the rest of Europe. ${ }^{2}$ Elderly people are and will be affected by multiple chronic conditions - that is, multimorbidity ${ }^{3}-$ and several mental disorders, ${ }^{4}$ even when dementia disorders are not taken into account. ${ }^{5}$ Multimorbidity is associated with mental health problems among elderly people ${ }^{6}$ and is often treated with polypharmacy. ${ }^{7}$ It seems likely that future home health care will increase among older people ${ }^{8}$ and that a high number of community-dwelling seniors
Correspondence: Åke Grundberg Sophiahemmet University, PO Box 5605, Lindstedtsvägen 8, SE-II4 86 Stockholm, Sweden

Email Ake.Grundberg@shh.se 
with multimorbidity will become a challenge in Swedish elder care ${ }^{9}$ and among those who provide home help services and home health care. ${ }^{10}$ In the present study, seniors with multimorbidity are referred to as clients or seniors because they are not defined as patients in this context.

Mental health problems among seniors have become a major public health issue in Sweden ${ }^{11,12}$ and in other highincome countries. ${ }^{13}$ The prevalence of mental disorders in seniors who live in communities is high, and may affect $30 \%-50 \%$ of this population. ${ }^{14,15}$ Multiple factors associated with psychogeriatric problems have been studied among older community patients, ${ }^{16}$ and for instance, depression has been related to being female, being unmarried, and to having somatic disease, functional disability, and a smaller social network. ${ }^{17,18}$ Further, anxiety symptoms have been associated with the female sex, chronic disease, and functional limitations. ${ }^{18}$ Seniors with multimorbidity are at risk of developing a generally low quality of life, ${ }^{19}$ psychological distress, ${ }^{3}$ and depressive disorders. ${ }^{20,21}$ Nevertheless, seniors with multimorbidity may lack access to health-promoting dialogues that could facilitate mental health. ${ }^{22}$

The increase in the senior population implies changing needs, indicating that many health care systems will face challenges regarding caring for seniors with mental disorders. ${ }^{23}$ The organizations that provide care and services to the very old vary between countries, depending on the structure of each one's health care system and its finances. ${ }^{24}$ In Sweden, the county councils are responsible for health care, and the municipalities handle all other care efforts, while the government bears responsibility for legislation. ${ }^{25}$ Swedish seniors ( $>65$ years of age) who remain in their own homes may be provided support through the municipal home help service, according to the Social Service Act (SFS 2001:453). ${ }^{26}$ This publicly funded support varies ${ }^{27}$ according to the client's needs and facilitates daily life in areas such as grocery purchases, food distribution, cleaning, and personal care. Before a senior can receive such support from a municipality, an assessment of his or her individual requirements must be made by a public home care officer, ${ }^{28}$ also known as care managers (CMs). The granted support is then provided in ordinary housing by nursing aides (NAs) or enrolled nurses ${ }^{10,29,30}$ or trained nursing assistants working as home care assistants (HCAs). These unlicensed personnel often work alone in the seniors' homes, where they provide personal care, services, and housekeeping, and they often relieve district nurses (DNs) in the administration of prescribed medication. ${ }^{31,32}$ Despite increasing numbers of seniors receiving home help services, there are fewer and fewer staff members who can provide this granted support. ${ }^{33}$ This implies that the workload for HCAs has increased, and they often face situations that demand more knowledge on a broader range of subjects. ${ }^{2}$ Although most HCAs have completed a high-school education (or equivalent), ${ }^{33}$ this staff may need increased knowledge in matters of mental illness among senior adults. ${ }^{34}$

In Swedish primary care, general practitioners (GPs) and DNs have the primary responsibility for health promotion activities. ${ }^{35}$ DNs work on health promotion and disease prevention among homebound patients, in addition to providing care to patients of all ages and medical diagnoses. ${ }^{36}$ The job of these registered nurses also involves prescribing certain medicines, technical materials, and equipment for patients with diabetes and incontinence. It is within a DN's prerogative to delegate the administration of medication to the HCAs providing social services; these nurses, further, cannot fulfill their responsibilities without delegating to HCAs the administration of chronically ill seniors' prescription medication. ${ }^{37}$ Therefore, DNs and HCAs are both present in a given senior's home, and the administration of medicine has become a matter that involves both health care and social service care ${ }^{38}$ Furthermore, caring for elderly persons with mental disorders presents a complex situation for the HCAs, ${ }^{24}$ and despite a high incidence of mental disorders among older adults, direct care personnel may be insufficiently prepared and trained in mental illness and geriatrics. ${ }^{39,40}$ In addition, previous research has concluded that training of NAs may promote quality of care for older adults with mental illness as well as improve personnel job satisfaction. ${ }^{41,42}$

The Swedish National Board of Health and Welfare states that older people with comprehensive and complex needs for care and support mostly remain in their homes, receiving that care and support from various providers and through intermittent hospitalizations. ${ }^{33}$ Even though seniors with multimorbidity are at risk of developing mental health problems such as depression, the current situation among seniors with mental disorders has been very little studied. Earlier studies have sought to increase the understanding of mental health care delivery in the primary care setting, ${ }^{43-45}$ or to determine whether seniors with mental disorders are provided with adequate home help services, ${ }^{24}$ or to report staff members' views of caring for patients experiencing late-life depression. ${ }^{46} \mathrm{HCAs}$ have rarely been the subject of investigation on their own. One reason for this may be that the idea that HCAs may play an active part in health promotion work for their clients is a new one. ${ }^{47}$ As HCAs often encounter homebound seniors, they may be pivotal in identifying those 
clients who are at risk of or are already experiencing mental health problems, and they are in a position to initiate actions that facilitate the early detection of mental health problems such as depression. Even so, limited research has been found targeting HCAs' involvement and specific training in the area of mental health. In order to increase the quality of care provided to homebound seniors with multimorbidity, it is important to understand HCAs' experiences of the ways in which mental health problems may be detected and mental health may be promoted within this population. In order to make progress in this area, the aim of this study was to describe HCAs' perspectives on detecting mental health problems and promoting mental health among communitydwelling seniors with multimorbidity.

\section{Methods Design}

In order to meet this study's aim, we chose a descriptive and qualitative design in which focus group interviews were used in the process of data collection. ${ }^{48}$ Qualitative research is designed to describe, interpret, and understand human experience and to describe the meaning that this experience has for the participant. ${ }^{49} \mathrm{~A}$ focus group interview gives the researcher an opportunity to understand several informants' differing points of view. ${ }^{50}$ The data from the focus group interviews were analyzed using a content analysis technique inspired by Graneheim and Lundman. ${ }^{51}$

\section{Participants}

The study examined the municipal home help services in one urban district in Sweden. Some informants visited older seniors with and without multimorbidity and mental health problems. Encounters with the older persons varied from single and multiple daily visits to a single visit with one older person that lasted for almost an entire day. Participants were selected according to a convenience sample technique, ${ }^{52}$ and the inclusion criterion was any experience caring for seniors with multimorbidity. The first author ( $\AA \mathrm{G})$ contacted the medically responsible nurses in 13 municipalities, who were sent written information about the study and its purpose. Four of those medically responsible nurses responded and referred us to the operations managers of five municipal home help services. The operations managers were then contacted by the first author to confirm their participation and to agree upon a place and time for an interview and on the nature of written content about the HCAs' participation in the study. Ultimately, five focus group interviews took place, with four to six participants in each group. The participants were all
Swedish-speaking HCAs from four different municipalities: 23 women and three men between 21 and 65 years of age. The HCAs were all unlicensed assistive personnel: 21 informants had an upper secondary education as assistant nurses three were NAs who had completed shorter education programs, and two lacked education in either health care or social services. Their professional experience as HCAs ranged between 6 months and 32 years. The HCAs worked part or full time, and all had experience providing home help services to seniors with multimorbidity.

\section{Data collection}

All focus group interviews began with the question: "How may mental health problems be detected among elderly people with multimorbidity?" The initial question was followed by: "How may mental health be promoted among these seniors?" Follow-up and probing questions were sometimes used in order to learn more about informants' experiences in this area and to facilitate dialogue and interaction in each group. At the end of each interview, the interviewer repeated the two main questions and asked whether the HCAs had anything to add. Each interview lasted between 44 and 64 minutes. All interviews were recorded and collected from May to December 2014.

\section{Analysis}

The interviews were transcribed verbatim and were subsequently reread several times to assess the material. Each transcript was coded and checked for correctness against the corresponding audio file. The resulting text was examined using an inductive, manifest, and latent content analysis inspired by Graneheim and Lundman, ${ }^{51}$ as described in a recent study. ${ }^{22}$ According to Sandelowski, ${ }^{53}$ important insights can emerge from the different ways in which different persons look at data in qualitative research. In this study, four authors in a research team read through the material separately to obtain a sense of the complete text. The research team then reread all interview transcripts to ensure consistency, keeping in mind the aim of the study and the content analysis. Units of text (eg, words, sentences, paragraphs) that answered the two research questions were marked, condensed into a description of their manifest content, and coded. The components of each focus group interview were lumped together and designated as a single unit. The codes were compared based on differences and similarities and organized into three categories, each with two subcategories which constituted the manifest content. As a final step, the underlying meaning (ie, the latent content) 
of the text was formulated into an overarching theme that encompassed all the categories (Table 1).

\section{Rigor}

The first author was responsible for all data collection and transcription, the main part of the analysis, and manuscript preparation. To increase the trustworthiness of the present study, all authors were involved in the entire research process and discussed the findings until consensus was reached.

\section{Ethics}

This study was approved by the Regional Ethical Review Board in Stockholm, Sweden (Nos. 2008/149-31, 2015/45$31)$. Ethical considerations were applied thoroughly at every step of the procedure. Both verbal and written information was provided about the study, and written consent was obtained from every participant. Participants were informed that their participation was voluntary and could be terminated at any time.

\section{Results}

Most HCAs stated that they were experienced in caring for clients with mental health problems such as anxiety, depression, sleep problems, and high alcohol consumption. The participants engaged in detailed discussions according to their experiences both negative and positive. Analysis of the data revealed an overarching theme that described how mental health problems may be detected and how to improve mental health: continuity provided by an accessible and competent team may increase social and physical activity. Findings are presented collectively in the three categories observation, collaboration, and social support in order to describe ways of detecting mental health problems as well as factors that may promote mental health (Table 1): activities in these categories emerged as ways of detecting mental health problems and promoting mental health.

\section{Observation}

Several HCAs articulated that good personal knowledge of the client was crucial to detecting mental health problems. Most participants explicitly indicated that continuity and continuous home visits were essential to noticing any changes in behavior or expressed emotions. Observing and evaluating a client's behavior and emotions constituted important sources of information in determining whether the HCAs should act to promote mental health. Knowledge about a senior's medical history was especially pivotal if HCAs were to detect mental health problems such as anxiety and depression. Several participants argued that mental health problems among seniors were to be expected, and that depression could be explained by various well-known causes, such as multiple chronic conditions, physical impairments, dementia, stroke, pharmacological treatment, constipation, social loneliness, high alcohol consumption, and being in need of care and support. Other HCAs had difficulty interpreting the causes and effects of alcohol use or misuse. The challenge was to evaluate whether the seniors became depressed because of their increased alcohol consumption or started to abuse alcohol after signs of depression and anxiety had already appeared. One participant described poor mental health as synonymous with depression, asserting that such illness could be explained in terms of interacting causes:

The more diseases and the more medications [...] the greater the risk that you end up there with depression [...] losing zest for life [...] having difficulty sleeping [...] and their appetite disappears [...]. The psyche suffers most because one suffers so many obstacles [...] If you become multimorbid and experience dizziness and take a lot of medicines that also have a lot of side effects, it affects the psyche very deeply. You may even take medications that make you constipated, and you can't eat as you normally do. It's also hard to get around, so they don't do things they used to do before $[\ldots]$ because of all these barriers.

An ocular observation of the client's personal appearance and home environment was performed in order to evaluate his or her behavior and to identify changed emotions that might reflect the development of poor mental health. Observing behavior involved identifying poor appetite, malnutrition, physical and social inactivity, and low inter-

Table I Results of the content analysis

\begin{tabular}{|c|c|c|c|c|c|c|}
\hline \multirow{3}{*}{$\begin{array}{l}\text { Theme } \\
\text { Category } \\
\text { Subcategory }\end{array}$} & \multicolumn{6}{|c|}{ Continuity provided by an accessible and competent team may increase social and physical activity } \\
\hline & \multicolumn{2}{|c|}{ Observation } & \multicolumn{2}{|l|}{ Collaboration } & \multicolumn{2}{|l|}{ Social support } \\
\hline & Behavior & Emotions & $\begin{array}{l}\text { Transmission of } \\
\text { information }\end{array}$ & Cooperation & Instrumental support & $\begin{array}{l}\text { Emotional } \\
\text { support }\end{array}$ \\
\hline Examples of codes & Inactivity & Fear of loneliness & Inform district nurse & Peer advice & $\begin{array}{l}\text { Contacting care } \\
\text { manager }\end{array}$ & $\begin{array}{l}\text { Decrease } \\
\text { sadness }\end{array}$ \\
\hline
\end{tabular}


est in personal hygiene or in the tidiness of their home. In these observations, several HCAs reported that they might find unopened boxes of food that HCAs had left on an earlier visit and empty boxes and bottles of wine; these were interpreted as signs of worsening mental health. A senior's consumption of alcohol might also be detected by HCAs during an ambulatory home visit responding to a senior who had fallen and was unable to rise from the floor. Some participants indicated that there were other not-so-obvious signs of mental health problems. for example, a client might seem depressed or stressed during a personal meeting with a well-known HCA:

Then there are signs that you see when you talk to them. They become easily stressed and feel unbalanced when [...] someone comes to them $[\ldots]$ and there you see at once $[\ldots]$ that there's something wrong.

Other HCAs described additional signs of worsening mental health: a senior may seem especially tired, have difficulty sleeping during the night, or want to stay in bed during the day. Further, several clients had themselves perceived that they had a decreased "sparkle" and interest in life and told HCAs so; they might even state that they no longer wished to live. Several HCAs identified as signs of declining mental health a client's increased suspicion or confusion, an apparently weakened short-term memory, and indications that they saw things or people that were not present. These clients seemed to encounter particular difficulty when interacting with new people, according to the participants:

We have many women here who may $[\ldots]$ find it difficult to meet people $[\ldots]$ in the beginning. But as soon as they begin to get to know us, it will be a little better [...] It is also a sign that there is something mentally [amiss].

Observing a client's emotions entailed evaluating identified or expressed emotions that were both expected and unexpected among seniors with multimorbidity and seniors with mental health problems. The emotions the HCAs reported observing among the seniors in focus were a general sadness, sadness combined with loneliness, fear of loneliness, insecurity, and verbal aggressiveness among those with cognitive impairments. Several HCAs argued that these emotions were difficult to evaluate; anxiety was especially difficult to separate from symptoms that the HCAs could also relate to the seniors' chronic conditions:

And that anxiety can, of course, also prove that there is some problem with the heart, or that it hurts [...]. It might not really $[\ldots]$ be the heart that hurts, but instead it hurts in the soul $[\ldots]$ this can show up as physical $[. .$.$] symptoms.$

Even though a client's emotions and state of mind seemed quite easy to evaluate, several HCAs stated that they had experienced difficulty dealing with a senior's expression of sadness or the wish that his or her life would end. There was generally a lack of time to initiate a dialogue about these seniors' mental health conditions, since the time allotted for each HCA's home visit was calculated based on the time that each granted task should take. The HCAs reported not knowing what to do or how to behave if a client became more emotional and cried, for instance, when a well-known HCA arrived in his or her home environment. Home visits are often planned to provide a specific form of support; this problem is related to the CM's decision making and to the priority of practical tasks:

So we feel the pressure of time because we cost money [...] so then you have to almost just put on the vacuum cleaner $[\ldots]$ even though this is someone who is crying [...] because the task is to vacuum.

\section{Collaboration}

Several HCAs viewed collaboration with colleagues and other health care professionals as important when they themselves lacked knowledge about how to detect and handle mental health problems or how to improve mental health. Such collaboration involved the transmission of information about a client's mental health status or about how to promote mental health. In fact, HCAs seemed dependent on effective cooperation with other actors in these matters. The HCAs reported that it was quite difficult for them to detect potential problems or to interact with seniors with various mental health problems: they depended on other actors to transmit information about changed behavior - to inform them, for instance, if a senior had become more emotional. Study participants seemed especially dependent on information from the responsible GP or DN about a senior's chronic conditions and current mental health status. Even though DNs often seemed to transmit information about a senior's mental health problems, several HCAs lacked guidance in how to respond to a client with mental health problems or in providing support for those with known anxiety or diagnosed depression:

It's really important that we get the right information, I think [...] from a doctor [...] before we go to them [...]. We must know exactly what the disease is [...] and how to treat that person. 
Participants also seemed dependent on their collaboration with the responsible $\mathrm{CM}$, with whom they apparently communicated only rarely, although HCAs wanted to transmit information about a client's changed behavior, alcohol consumption, and their own evaluation of the granted support. If a senior could not transmit information about his or her own mental health status, the HCAs usually were contacted by relatives or neighbors, who might report changed behavior and the impression that the client's mental health had declined. A few HCAs mentioned that Swedish legislation about transmitting information could pose a barrier when HCAs wish to inform health care professionals or talk to relatives or neighbors about a client:

So even if you want to sound the alarm [...] and you want to try to circumvent potential problems, you must always pursue each person's best interests, as well [...]. For example, I might decide that now I have to [...] break a little confidentiality here because it serves the person's best interests.

Although HCAs viewed their collaboration with colleagues as essential, there seemed to be no planned time for mutual information sharing about clients receiving granted support. The HCAs especially highlighted the importance of a forum, currently nonexistent, through which to transmit information about a senior's state of mind and to share suggestions about how colleagues could provide support during the next home visit:

We ought to all just sit down and talk a little bit about some of our joint clients. And if I knew you were going over there in the morning, I could tell you, "She was sad today [...] can you help her by going out with her [...] or making food for her $[\ldots]$ so she won't need to cry again?"

Cooperation was another aspect of collaboration, since most participants reported that they did not have practical support or contact with other actors close to the senior in focus. The improvement they wanted in their cooperation with health care professionals such as DNs was crucial; HCAs seemed to want an agreement that would clarify each actor's responsibility in matters of mental health. Closer and more pragmatic cooperation with DNs constituted one way to improve HCAs' knowledge of mental health, according to most participants. Further, they seemed to think that working more closely with DNs would provide opportunities for questions related to a senior's mental health and for additional intermittent supervision regarding how multimorbidity may affect mental health and the best ways to deal with it:

Supervision in how to handle $[\ldots]$ our mentally ill $[\ldots]$ people, clients, patients with multiple diagnoses $[\ldots]$. That would be great!

Several participants stated that they had no access to a forum for cooperation with their colleagues, even though they seemed to consult with them by phone between home visits and during lunch breaks. Other participants gave examples of intermittent and planned forums for learning about their colleagues' experiences in the field:

Then one can get some advice too [...] based on other people's experiences [...]. Then we can try this, maybe, and $[\ldots]$ see if it works $[\ldots]$ so maybe we can come up with a solution together.

Some participating HCAs were unable to name specific actors whom they could contact when they needed support or wanted to discuss a client they were concerned about. The participants considered cooperation with mental health care professionals especially important if they were to increase their own knowledge about mental health issues:

Well, then it must surely be a psych team that you have access to [...]. This would provide more knowledge [...]. We need more knowledge! So we need to be connected to a psychiatric team that could sort of supervise us.

\section{Social support}

According to several participants, seniors with multimorbidity often live alone and need different kinds of social support, including both instrumental and emotional support. Most HCAs cited living alone and feeling lonely as reasons why seniors might develop mental health problems like depression. Accordingly, some HCAs understood that their own presence and work made a difference because they could break up periods of loneliness simply by visiting a client and providing support with practical everyday tasks. Other participants stated that it was difficult to provide support that could improve mental health and that they needed greater knowledge in this area, as well as more time for dialogue with clients, for conversations that might help improve mental health:

I mean, okay, if they the clients now live at home $[\ldots]$ and are healthy and have no mental problems [...] then we need to have more time with them so that we can help them [...]. We do not have that time. 
Instrumental support entails practical actions that promote mental health, such as sitting down to chat over a cup of coffee. It seemed especially important to many HCAs that homebound seniors have an opportunity to leave their home environment in order to increase their social contacts or physical activity:

Thus, most people are alone [...] and it's loneliness that affects mental health, actually! They need this social part. Through this social interaction [...] we can actually make sure that they get to walk in the yard [...] to actually talk $[\ldots]$ or we can drink coffee with them.

Another component of instrumental support was body massage; still another was helping a client to contact a mental health care provider when a senior expressed suicidal thoughts or to contact a physician or nurse in primary health care to evaluate a senior's pharmacological treatment. Some HCAs argued that polypharmacy was itself a reason why a client's mental health might be poor:

It's rare that anyone looks at the patient and asks, "Do you need all these drugs?" [...] or asks, "Can we stop some medications?" [...]. It could also be, among those who don't feel so good or eat so well [...] that they don't feel good mentally just $[\ldots]$ because there is so much happening in the body.

Contacting a library to request a book and reading to the senior from a newspaper were other actions that HCAs reported could help avert loneliness and thus promote mental health. The HCAs repeatedly mentioned that they had no time for such social support because clients were rarely granted support specifically meant to disrupt loneliness or promote mental health. Even so, few HCAs said that they could contact the responsible chief or CM to highlight the senior's need for social support or to suggest that the granted support should be evaluated or that the senior needed other assistance aimed at promoting mental health. Being granted time for company during meals or for physical activities such as walks and social daycare was a form of (rarely granted) support that the HCAs said could improve mental health and prevent depression. One participant indicated that it was often difficult (though not impossible) to convince a client of the importance of social activities:

They need to have confidence in the person [HCA] [...] so we can help get them on the right path. And it's the same thing $[\ldots]$ the client goes to social daycare now: I tried to convince her that it would be good for her, and it's worked out great.

Emotional support is another kind of social support that most participants highlighted as a means of promoting mental health. Several HCAs repeatedly stated that it was crucial to cultivate a trustful relationship with the seniors and that this required time, in combination with interpersonal skills such as perception and the ability to listen actively and ask questions about what might help the senior feel better more generally. HCAs indicated that it was especially important to have the goal of decreasing clients' feelings of loneliness and increasing their feelings of security about home help services and their overall purpose:

The client can know that they're not alone [...] there is someone who cares about them $[\ldots]$ someone who will help and whom they can turn to.

Several participants repeatedly stated that dialogue was the most important way to improve mental health: the seniors in focus needed professional partners in dialogue, such as psychologists and social workers. Some HCAs highlighted their own role as dialogue partners as a means of both detecting mental health problems and promoting mental health:

So after you start talking to them [...] when they feel a little bit calmer [...] you can see whether there's a question mark, something amiss that has to do with mental health.

The dialogues HCAs engaged in with their clients aimed to identify a client's state of mind so that the HCA could establish trust and provide hope for the future. Even though the HCAs seem to lack time to sit down for a conversation that could promote mental health, some reported that such dialogues could take place while HCAs were preparing food, cleaning, or walking outside with the client. The content of some such dialogues seemed to center on joyful matters in the seniors' lives, aiming to distract them from anxiety or to decrease any sadness they had expressed; others focused on helping the senior verbalize current emotions. With this in mind, it seemed crucial that an HCA talk in a relaxed way and that dialogue involve active listening and probing questions that show personal interest in the senior's expression of matters that troubled them. Such dialogue could also lead to the detection of mental health issues:

And then other things may emerge, too $[\ldots]$ that they are keeping within themselves. Because when you start talking and start a conversation $[\ldots]$ one thing leads to another. Yes, it could be [...] anything and that may be annoying, as they 
carry on $[\ldots]$ that's hard. But then maybe it all comes out: they may need to talk, speak about themselves [...] and feel that there is somebody who listens.

\section{Discussion}

This study illuminated HCAs' experiences caring for seniors with multimorbidity and these care providers' perspectives on detecting mental health problems and promoting mental health among these seniors. Participants related both positive and negative experiences of addressing mental health among homebound seniors, and their discussions indicate that they were engaged in these matters. The primary results show that the participants had encountered mental health problems such as depression, anxiety, and difficulty sleeping among seniors with multiple chronic conditions. Several participants seemed to think that such mental health problems were to be expected among most of their clients, especially those who were living alone with somatic diseases and polypharmacy. This perception may stem from participants' experiences caring for elderly people or from stereotyping beliefs about aging and illnesses. ${ }^{54}$ The HCAs mentioned causes, or risk factors, that related first and foremost to multiple chronic conditions, feelings of loneliness, and social isolation. Concerning mental health and aging, a previous study reported that community-dwelling seniors with multimorbidity stated that mental health problems were considered a normal part of aging. ${ }^{55}$ Such a belief about the correlation between aging and mental health problems cannot be considered acceptable, for negative stereotypes of aging may translate into age discrimination and further social exclusion and hence into worsening mental and physical health. ${ }^{54}$ On the other hand, people's positive attitudes toward and affirmative beliefs about senior adults and aging appear to bolster seniors' mental health. ${ }^{56}$

Above all, participants indicated that good personal knowledge of a senior (and his or her medical history) was the most important factor in HCAs' ability to observe changes in client behavior, including altered emotions that could be warning signs of worsening mental health. Such signs included negative feelings, alcohol abuse, not eating, and not maintaining good personal hygiene. It was especially important to participants that they have the ability to observe the client's home environment in order to evaluate the client's level of interest in keeping it tidy. Continuity among HCAs' home visits was crucial if an HCA was to get to know a person well and to fulfill the important prerequisite of evaluating and comparing a senior's condition from one visit to the next. The HCAs especially highlighted that continuity of care was essential to detecting mental health problems and to addressing seniors' condition if they stated that they no longer had a desire to live. These findings should be compared with those of a previous study showing that continuity is important not only in detecting mental health issues but continuity of care, knowledge, and staff competence are also crucial to client satisfaction with the care older people receive in their homes. ${ }^{57}$

The HCAs were unsure whether the seniors in focus used alcohol because they were depressed or became depressed because of their alcohol consumption. HCAs apparently needed to interpret and explain the cause-and-effect relation in situations of alcohol abuse or self-medicating among this group of seniors. These discussions align with a previous study's finding of a direct relationship between alcohol abuse or dependence and major depression. ${ }^{58}$ Further, problems with alcohol may lead to an increased risk of major depression, which can be explained according to a self-medication model and by the fact that major depression may lead to an increased risk of alcohol abuse or dependency. ${ }^{58}$ It is therefore important that HCAs be provided with support and supervision in managing clients with alcohol abuse or dependency, since these clients may suffer from undetected major depression. It should also be noted that many seniors with multimorbidity are prescribed several drugs that may interact with alcohol, so recognized alcohol abuse should therefore be considered by the responsible physician and DN in home health care. The evaluation of medical treatment seems especially important among GPs, since these physicians are the main prescribers of psychotropic drugs to older people. ${ }^{59}$

It appears that the HCAs compared various signs of cognitive impairments and symptoms of dementia, depression, or psychosis. HCAs further reported that it was difficult to separate cognitive impairments from the physical symptoms of some somatic diseases. Previous studies have shown similar findings: numerous factors relate to psychogeriatric symptomatology in elderly people with physical illnesses, ${ }^{16}$ and mental health in old age is particularly related to several psychological, sociodemographic, and somatic factors, which may explain the reason for the low rate of detection of mental problems. ${ }^{60}$ Even though it is not HCAs' primary responsibility to detect mental health problems among their clients, it is essential that these staffers' day-to-day observations of current symptoms, changed behavior, and suicidal thoughts be taken into account when responsible health care professionals evaluate prescribed medication; doing so will provide a broader perspective that will aid the responsible physician 
in diagnosing dementia or mental health problems such as depression. However, continuous quality improvement in home care can take place only if all the actors involved learn from each other. HCAs' personal knowledge about their clients is vital because HCAs are the care providers closest to the action taking place in a client's home. ${ }^{47}$

According to participants in this study, social support constitutes an important mental health-promoting initiative because social isolation and feelings of loneliness are wellknown causes of or risk factors for mental health problems among these clients, who mostly live alone. In the data analysis, two subcategories of social support emerged: instrumental support and emotional support. Instrumental support related to practical tasks that the client once performed but was now unable to without assistance (eg, the administration of medicine). The HCAs' suggestions regarding instrumental support indicated that they thought it was crucial to break clients' social isolation and to increase their physical activity, mainly through oversight, home visits, dialogue, social daycare, and walking outdoors. However, some participants reported that it was sometimes difficult to motivate clients to participate in such social activities. According to the participants, clients with mental health problems were rarely granted assistance that included social support with the goal of alleviating social isolation or of increasing physical activity. These statements align with the findings of previous studies that have highlighted the importance of existential belonging, as well as the fact that seniors over age 65 with mental disorders generally have no access to daily activity centers in the community ${ }^{61}$; people with mental health issues struggle for social integration in the community. ${ }^{62}$ Other researchers stress that older adults who receive home care do not receive support for regular physical activity, ${ }^{63}$ even though it clearly benefits senior adults mentally and physically. ${ }^{47}$ The emotional support that participants advocated in the present study related primarily to dialogues that could distract clients from negative and unwanted emotions or change their mood; important components in such dialogues are the HCAs' active listening, asking questions to confirm understanding, and demonstrating personal interest in the clients. These dialogues, further, should have an unstructured form without an explicit or conscious aim or objective. Our finding should be compared to a previous systematic review and synthesis of qualitative studies, indicating that to experience care as something positive, elderly persons need to be acknowledged for who they are and feel appreciated, as well as given the opportunity to contribute to their own decisionmaking and maintain their relationships. ${ }^{64}$ Ultimately, even though the HCAs offered various suggestions on mental health-promoting initiatives related to social support, it is important that care providers understand what each client values in life and how that client makes sense of changes in his or her life situation. ${ }^{65}$ Further, staff members working with mental health care in the community need to ensure that clients with mental health issues also develop a sense of belonging in the community by helping these clients grow their social networks and achieve social integration. ${ }^{62}$

In contrast, although HCAs indicated that their tasks were associated with CMs' decision-making to organize the delivery of granted home help services, participants rarely contacted their CMs about needs assessment in situations of declining mental health or about the need for social support to improve a client's mental health. According to chapter 5, $\S 5$ of the Social Services Act (SFS 2001:453) [SOL], the social board should ensure that older people receive good housing and provide those who need it with support and help in their homes, along with other easily accessible services. ${ }^{26}$ Arguably, HCAs should be able to provide feedback to the CMs who would assist them in evaluating the granted support when a client's personal needs have changed. Also valuable would be scheduled time for HCAs to perform tasks that constitute social support with the purpose of improving mental health.

Another finding of the present study was that collaboration between DNs and CMs was crucial. According to the participants, a DN could transfer and respond to information about a client's behavior and emotions, as well as supervise HCAs in managing clients with mental health problems. From the HCAs' perspective, a CM was in a position to grant assignments in a way that increases the time HCAs have for activities that promote mental health and facilitate dialogue, such as increasing social and physical activities. The participants expressed a need for collegiality and stressed the importance of sharing the responsibility and decision-making about client tasks based on the HCAs' needs assessment. Collaboration and teamwork with health care professionals such as DNs and social services personnel emerged as especially crucial to transferring information about a client's changed behavior and emotions. According to several HCAs, there was no forum through which HCAs, DNs, and CMs could discuss issues or transfer and respond to information about a client. In addition, communication among health care professionals is important to improving health care among homebound seniors with mental and behavioral conditions. ${ }^{66}$

Participants in the present study were uncertain whose responsibility it was to promote mental health or to diagnose 
and treat mental health problems when they arise. This may explain why participants in this study seemed uncertain about whom they should contact first if a client's mental health deteriorated. These findings may also reflect the difficulties the HCAs perceived in providing care and support to a heterogeneous population of elderly people with multiple chronic conditions; perhaps, that was why HCAs expressed a desire for care coordination with actors such as DNs. This finding aligns with previous research, highlighting the importance of care coordination and health promotion among persons with multimorbidity. ${ }^{47}$ Other researchers have stated that multidisciplinary care is essential and should include the development of a comprehensive education system for all those involved in caring for an aging population. ${ }^{46,67}$ Several researchers have suggested that interprofessional collaboration constitutes a method of improving health because it involves a comprehensive team of experts (both health care professionals and social workers) who work collaboratively toward the shared goal of treating a person with complex needs in the community. ${ }^{67-71}$ Personal meetings with DNs may be useful when clients are in poor health, ${ }^{72}$ and such arenas for collaboration increase the opportunity for HCAs to receive supervision and to ask questions about medical ${ }^{32}$ and mental health issues.

According to further findings in the present study, personal resources appeared to be an important prerequisite for both detecting mental health problems and promoting mental health. Several HCAs repeatedly stated that they lacked time for such assignments because they were responsible for tasks related to household and personal care, and they were constrained by the limited time allotted for these tasks: those organizing the assistance in clients' homes planned such assignments to fit into specific time slots without allowing for addition interpersonal interaction. Specifically, participants lacked time for dialogue with clients through whom they could assess how a client was feeling or adequately comfort a sad client. This lack of time and the tight schedule may also be the reason why some HCAs seemed to have distanced themselves from clients in need of comfort or conversation about their mental health. In these cases, HCAs may decide to focus on the specific type of granted support they are supposed to provide, such as cleaning, rather than becoming attached to clients with whom they had little time to converse and truly engage. ${ }^{24}$ This finding about time aligns with the findings in our previous study indicating that seniors with multimorbidity preferred accessible interlocutors who had time for conversations that could promote mental health. ${ }^{22}$ The perceived lack of time could also reflect that HCAs must perform time-consuming tasks related to their delegated responsibility for administering medication and other care to several clients. ${ }^{32}$ However, since relationships with clients were important to personal knowledge and were crucial in detecting worsening mental health, HCAs may be caught between different interests related to ethical challenges in their granted assignments, including efforts to provide quality care to several clients in one work shift.

In order to obtain a varied sample, the study initially applied a convenience and purposive sampling technique. However, we encountered challenges in recruiting enough HCAs who had time for a focus group interview to assign a moderate number of participants to each group. This resulted in a convenience sample ${ }^{52}$ of mostly women of various ages and levels of experience in home help services and in caring for clients with multimorbidity. This may be both a weakness and strength in the present study. One limitation consists of the voluntary nature of study participation ${ }^{73}$ and the further risk that the most experienced HCAs in this area were recruited. Focus group interviews were considered a suitable method of data collection; a distinct feature of this method is its group dynamics through social interaction, which may facilitate participants' elucidation and further exploration of their perspectives on a specific topic. ${ }^{48}$ Given the limitations in accessibility to more HCAs of both sexes, along with the final sample size, the data include a fair amount of variation in experience; thus, the generalizability increases. The interview guide was designed specifically to give participants the opportunity to discuss and share both negative and positive experiences with their colleagues. This approach in data collection was successful in eliciting both depth and breadth of data. However, the findings cannot be generalized to other types of staff in elder care, and conclusions must therefore be drawn carefully, considering the participants' context.

\section{Conclusion}

The results indicate that the HCAs had knowledge about certain risk factors for mental health problems even though they seemed insecure about which health professionals had primary responsibility for their clients' mental health. They were often able to detect early signs of mental health problems even though good personal knowledge and continuity in home visits were needed in order to do so. When it came to mental health promotion, HCAs' suggestions were related to the goal of alleviating social isolation, decreasing feelings of loneliness, and increasing physical activity. The study also indicates that the HCAs seemed dependent on supervision from DNs and on CMs' decision-making about the granted support; HCAs relied on these professionals to schedule 
assignments in a way that would facilitate the detection of mental health problems and allow mental health promotion among this population. The results reported here present new knowledge about the opportunities and difficulties in the work of promoting mental health faced by staffers who meet clients on a regular basis. We suggest multidisciplinary and interprofessional approaches as means of facilitating the early detection of mental health problems and of increasing HCAs' competence in mental health promotion among their clients.

\section{Relevance to clinical practice}

Taking advantage of - and not underestimating - HCAs' experience and competence vis-à-vis a client's behavior and emotions is important because their observations may reflect worsening mental health over time. Investments should therefore be made to provide HCAs with the tools and skills they need to support clients with mental health problems and to help them remain integrated in their communities.

\section{Acknowledgments}

The authors would like to thank all the HCAs who shared their experiences and participated in present study. This work was financially supported by the National Health Care Science Postgraduate School, the Swedish Research Council (No. 523-2012-2291), and the Sophiahemmet Foundation.

\section{Disclosure}

The authors report no conflicts of interest in this work.

\section{References}

1. Statistical news from Statistics Sweden. The future population of Sweden 2014-2060. Available from: http://www.scb.se/en_/Finding-statistics/ Statistics-by-subject-area/Population/Population-projections/Populationprojections/Aktuell-Pong/14505/Behallare-for-Press/372727/. Accessed April 30, 2015.

2. Eurostat. Population and population change statistics. Available from: http://ec.europa.eu/eurostat/web/population-demography-migrationprojections/population-data. Accessed April 30, 2015.

3. Fortin M, Bravo G, Hudon C, Lapointe L, Dubois MF, Almirall J. Psychological distress and multimorbidity in primary care. Ann Fam Med. 2006;4(5):417-422.

4. Mechakra-Tahiri S, Zunzunegui MV, Preville M, Dube M. Social relationships and depression among people 65 years and over living in rural and urban areas of Quebec. Int $J$ Geriatr Psychiatry. 2009;24(11):1226-1236.

5. Martinsson G, Wiklund-Gustin L, Fagerberg I, Lindholm C. Mental disorders affect older persons in Sweden-a register-based study. Int $J$ Geriatr Psychiatry. 2011;26(3):277-283.

6. Jones SMW, Amtmann D, Gell NM. A psychometric examination of multimorbidity and mental health in older adults. Aging Ment Health. 2015:1-9.

7. Johnell K, Fastbom J, Rosén M, Leimanis A. Inappropriate drug use in the elderly: a nationwide register-based study. Ann Pharmacother. 2007;41(7):1243.
8. Meyer J, Sturdy D. Exploring the future of gerontological nursing outcomes. J Clin Nurs. 2004;13(6b):128-134.

9. Socialstyrelsen (The Swedish National Board of Health and Welfare). Varrd och omsorg om äldre. Lägesrapport 2012 [Care for the Elderly. Report of the Situation 2012]. Stockholm: Socialstyrelsen; 2012. Swedish.

10. Socialstyrelsen (The Swedish National Board of Health and Welfare). Hemsjukvård iförändring: en kartläggning av hemsjukvården i Sverige och förslag till indikatorer [Home Healthcare in Transition: A Survey of Home Care in Sweden and Proposed Indicators]. Stockholm: Socialstyrelsen; 2008. Swedish.

11. Berleen G. A healthier elderly population in Sweden! Available from: http://envejecimiento.csic.es/documentos/documentos/suecia-ahealthierelderly-01.pdf. Accessed April 29, 2015.

12. Socialstyrelsen (The Swedish National Board of Health and Welfare). Äldres psykiska hälsa [Older People's Mental Health]. Stockholm: Socialstyrelsen; 2008. Swedish.

13. World Health Organization. Good health adds life to years. Global brief for World Health Day 2012; 2012. Available from: www.who.int/ageing/ publications/whd2012_global_brief/en/index.html. Accessed April 10, 2015.

14. Skoog I. Psychiatric epidemiology of old age: the H70 study - the NAPE Lecture 2003. Acta Psychiatr Scand. 2004;109(1):4-18.

15. Trollor JN, Anderson TM, Sachdev PS, Brodaty H, Andrews G. Prevalence of mental disorders in the elderly: the Australian National Mental Health and Well-Being Survey. Am J Geriatr Psychiatry. 2007;15(6):455-466.

16. Olivera J, Benabarre S, Lorente T, et al. Detecting psychogeriatric problems in primary care: factors related to psychiatric symptoms in older community patients. Ment Health Fam Med. 2011;8(1):11-19.

17. Bergdahl E, Allard P, Alex L, Lundman B, Gustafson Y. Gender differences in depression among the very old. Int Psychogeriatr. 2007;19(6):1125-1140.

18. Vink D, Aartsen MJ, Schoevers RA. Risk factors for anxiety and depression in the elderly: a review. J Affect Disord. 2008;106(1-2): $29-44$.

19. Fortin M, Lapointe L, Hudon C, Vanasse A, Ntetu AL, Maltais D. Multimorbidity and quality of life in primary care: a systematic review. Health Qual Life Outcomes. 2004;2:51.

20. McEvoy P, Barnes P. Using the chronic care model to tackle depression among older adults who have long-term physical conditions. J Psychiatr Ment Health Nurs. 2007;14(3):233-238.

21. Spangenberg L, Forkmann T, Brähler E, Glaesmer H. The association of depression and multimorbidity in the elderly: implications for the assessment of depression. Psychogeriatrics. 2011;11(4):227-234

22. Grundberg A, Ebbeskog B, Gustafsson SA, Religa D. Mental health-promoting dialogues from the perspective of communitydwelling seniors with multimorbidity. $J$ Multidiscip Healthc. 2014;7: 189-199.

23. Clinton M. New directions in mental health practice with older people: Canadian strategies for mental health reform. Int J Older People Nurs. 2007;2(2):155-158.

24. Martinsson G, Wiklund-Gustin L, Lindholm C, Fagerberg I. Being altruistically egoistic-nursing aides' experiences of caring for older persons with mental disorders. Int J Qual Stud Health Well-being. 2011;6(4).

25. Ekwall A. Äldres hälsa och ohälsa: en introduktion till geriatrisk omvårdnad [Older Persons' Health and Ill-Health: An Introduction to Geriatric Care]. Lund: Studentlitteratur; 2010. Swedish.

26. Socialtjänstlag. [The Social Services Act]. Vol SFS 2001:453. Stockholm: Socialdepartementet. Swedish.

27. Johansson B, Malmberg B. Gerontology in Sweden. A research and institutional perspective. Contemp Gerontol. 2004;11(2):55-59.

28. Pajalic Z, Persson L, Skovdahl K, Westergren A. Facilitating change, the decision-maker's views of municipality organized food distribution to elderly people living at home and suggestions for development [Elektronisk resurs]: a participatory action research study. Public Admin Res. 2012;1(1):14-23. 
29. Socialstyrelsen (The Swedish National Board of Health and Welfare). Ädelreformen - Slutrapport [The "Ädel Reform" - Final Report]. Stockholm: Socialstyrelsen; 1996. Swedish.

30. Socialstyrelsen (The Swedish National Board of Health and Welfare). Äldre och personer med funktionsnedsättning - regiform år 2013. Vissa kommunala insatser enligt socialtjänstlagen. SVERIGES OFFICIELLA STATISTIK [Elderly and Persons with Impairments - Management form 2013. Some Municipal Services According to the Social Services Act. OFFICIAL STATISTICS OF SWEDEN]. Stockholm: Socialstyrelsen; 2014. Swedish.

31. Astvik W. Relationer som arbete: Förutsättningar för omsorgsfulla möten i hemtjänsten [Relating as a Primary Task: Prerequisites for Sustainable Caring Relations in Home-Care Service]. Stockholm: Stockholm University; 2003. Swedish.

32. Gransjön Craftman A, Hammar LM, von Strauss E, Hillerås P, Westerbotn M. Unlicensed personnel administering medications to older persons living at home: a challenge for social and care services. Int J Older People Nurs. 2014.

33. Socialstyrelsen. The Swedish National Board of Health and Welfare. Tillståndet och utvecklingen inom hälso- och sjukvård och socialtjänst. Lägesrapport 2014 [The Present Situation in Healthcare and Social Services, 2014]. Stockholm: Socialstyrelsen; 2014. Swedish.

34. Modig S, Midlov P, Kristensson J. Depressive symptoms among frail elderly in ordinary living: who is affected and who is treated? Aging Ment Health. 2014;18(8):1022-1028.

35. Strandberg EL, Ovhed I, Borgquist L, Wilhelmsson S. The perceived meaning of a (w)holistic view among general practitioners and district nurses in Swedish primary care: a qualitative study. BMC Fam Pract. 2007;8:8

36. Wilhelmsson S, Lindberg M. Health promotion: facilitators and barriers perceived by district nurses. Int J Nurs Pract. 2009;15(3):156-163.

37. Craftman AG, von Strauss E, Rudberg SL, Westerbotn M. District nurses' perceptions of the concept of delegating administration of medication to home care aides working in the municipality: a discrepancy between legal regulations and practice. J Clin Nurs. 2013;22(3-4):569-578.

38. Bradford J. Medication administration in the domiciliary care setting: whose role? Br J Community Nurs. 2012;17(11):537-542.

39. Molinari VA, Merritt SS, Mills WL, et al. Serious mental illness in Florida nursing homes: need for training. Gerontol Geriatr Educ. 2008;29(1):66-83.

40. Morris DL, Mentes J. Geropsychiatric nursing education: challenge and opportunity. J Am Psychiatr Nurses Assoc. 2006;12(2):105.

41. Yeatts DE, Cready C, Swan J, Shen Y. The perception of "training availability" among certified nurse aides: relationship to CNA performance, turnover, attitudes, burnout, and empowerment. Gerontol Geriatr Educ. 2010;31(2):115-132.

42. Glaister JA, Blair C. Improved education and training for nursing assistants: keys to promoting the mental health of nursing home residents. Issues Ment Health Nurs. 2008;29(8):863-872.

43. Barker S, Heaslip V, Chelvanayagam S. Addressing older people's mental health needs in the community setting. Br J Community Nurs. 2014;19(5):234-238.

44. Haddad M, Plummer S, Taverner A, et al. District nurses' involvement and attitudes to mental health problems: a three-area cross-sectional study. J Clin Nurs. 2005;14(8):976-985.

45. Rouchell AM. Major depression in primary care. Ochsner J. 2000; 2(2):79-84.

46. Hassall S, Gill T. Providing care to the elderly with depression: the views of aged care staff. $J$ Psychiatr Ment Health Nurs. 2008;15(1):17-23.

47. Muramatsu N, Madrigal J, Berbaum ML, et al. Co-learning with home care aides and their clients: collaboratively increasing individual and organizational capacities. Gerontol Geriatr Educ. 2015;36(3):261-277.

48. Krueger RA, Casey MA. Focus Groups: A Practical Guide for Applied Research. Thousand Oaks, CA: Sage Publications; 2009.

49. Creswell JW. Qualitative Inquiry and Research Design: Choosing Among Five Approaches. Thousand Oaks, CA: Sage Publications; 2007.

50. Kvale S, Brinkmann S. Den kvalitativa forskningsintervjun [The Qualitative Research Interview]. Lund: Studentlitteratur AB; 2009. Swedish.
51. Graneheim UH, Lundman B. Qualitative content analysis in nursing research: concepts, procedures and measures to achieve trustworthiness. Nurse Educ Today. 2004;24(2):105-112.

52. Dahlgren L, Emmelin M, Winkvist A, Lindhgren M. Qualitative Methodology for International Public Health. Umeå: Epidemiology and Public Health Sciences, Department of Public Health and Clinical Medicine, Umeå University; 2007.

53. Sandelowski M. The call to experts in qualitative research. Res Nurs Health. 1998;21(5):467-471.

54. Stephan Y, Sutin AR, Terracciano A. How old do you feel? The role of age discrimination and biological aging in subjective age. PLoS One. 2015;10(3): 0119293

55. Grundberg A, Ebbeskog B, Dahlgren MA, Religa D. How communitydwelling seniors with multimorbidity conceive the concept of mental health and factors that may influence it: a phenomenographic study. Int J Qual Stud Health Well-being. 2012;7:1-13.

56. Levy BR, Slade MD, Kunkel SR, Kasl SV. Longevity increased by positive self-perceptions of aging. J Pers Soc Psychol. 2002;83(2):261-270.

57. Karlsson S, Edberg AK, Jakobsson U, Hallberg IR. Care satisfaction among older people receiving public care and service at home or in special accommodation. J Clin Nurs. 2013;22(3-4):318-330.

58. Fergusson DM, Boden JM, Horwood LJ. Tests of causal links between alcohol abuse or dependence and major depression. Arch Gen Psychiatry. 2009;66(3):260-266.

59. Martinsson G, Fagerberg I, Wiklund-Gustin L, Lindholm C. Specialist prescribing of psychotropic drugs to older persons in Sweden-a registerbased study of 188,024 older persons. BMC Psychiatry. 2012;12:197.

60. Olivera J, Benabarre S, Lorente Tf, et al. Prevalence of psychiatric symptoms and mental disorders detected in primary care in an elderly Spanish population. The PSICOTARD Study: preliminary findings. Int J Geriatr Psychiatry. 2008;23(9):915-921.

61. Martinsson G, Fagerberg I, Lindholm C, Wiklund-Gustin L. Struggling for existence-life situation experiences of older persons with mental disorders. Int J Qual Stud Health Well-being. 2012;7.

62. Granerud A, Severinsson E. The struggle for social integration in the community - the experiences of people with mental health problems. J Psychiatr Ment Health Nurs. 2006;13(3):288-293.

63. Yan T, Wilber KH, Wieckowski J, Simmons WJ. Results from the healthy moves for aging well program: changes of the health outcomes. Home Health Care Serv Q. 2009;28(2-3):100-111.

64. Bridges J, Flatley M, Meyer J. Older people's and relatives' experiences in acute care settings: systematic review and synthesis of qualitative studies. Int J Nurs Stud. 2010;47(1):89-107.

65. McCormack B. Person-centredness in gerontological nursing: an overview of the literature. J Clin Nurs. 2004;13(3a):31-38.

66. Gleason HP, Coyle CE. Mental and behavioral health conditions among older adults: implications for the home care workforce. Aging Ment Health. 2015:1-8.

67. Arai H, Ouchi Y, Yokode M, et al. Toward the realization of a better aged society: messages from gerontology and geriatrics. Geriatr Gerontol Int. 2012;12(1):16-22.

68. Vanderbilt AA, Dail MD, Jaberi P. Reducing health disparities in underserved communities via interprofessional collaboration across health care professions. J Multidiscip Healthc. 2015;8:205-208.

69. Markle-Reid M, McAiney C, Forbes D, et al. Reducing depression in older home care clients: design of a prospective study of a nurse-led interprofessional mental health promotion intervention. BMC Geriatr. 2011;11:50

70. Dyer CB, Hyer K, Feldt KS, et al. Frail older patient care by interdisciplinary teams: a primer for generalists. Gerontol Geriatr Educ. 2003;24(2):51-62.

71. Berk M, Berk L, Denton T. Psychiatric disorders in primary care. Aust N Z J Psychiatry. 2014;48(6):497-499.

72. Kraus K. Sven, Inter-organisational Relationships and Control: A Case Study of Domestic Care of the Elderly. Stockholm: Economic Research Institute, Stockholm School of Economics (EFI); 2007.

73. Faugier J, Sargeant M. Sampling hard to reach populations. JAdv Nurs. 1997;26(4):790-797. 


\section{Publish your work in this journal}

The Journal of Multidisciplinary Healthcare is an international, peerreviewed open-access journal that aims to represent and publish research in healthcare areas delivered by practitioners of different disciplines. This includes studies and reviews conducted by multidisciplinary teams as well as research which evaluates the results or conduct of such teams or healthcare processes in general. The journal covers a wide range of areas and welcomes submissions from practitioners at all levels, from all over the world. The manuscript management system is completely online and includes a very quick and fair peer-review system. Visit http://www.dovepress.com/testimonials.php to read real quotes from published authors.

Submit your manuscript here: http://www.dovepress.com/journal-of-multidisciplinary-healthcare-journal 